\title{
Planificación para el desarrollo con enfoque prospectivo en Bolivia, Ecuador, Guatemala y Perúi
}

\author{
Planning for development with prospective approach in Bolivia, \\ Ecuador, Guatemala y Peru
}

\author{
Álvaro Cristian Sánchez Mercado ${ }^{2}$
}

\begin{abstract}
RESUMEN
La presente investigación realizauna exploración respecto de algunos conceptos ligados al Planeamiento Estratégico de un país, y, la comparación de los Sistemas de Planeamiento y los Planes Estratégicos de Desarrollo de Bolivia, Ecuador, Guatemala y Perú.Para ello, en una primera parte se ha hecho una revisión sistemática de las definiciones y en una segunda parte una revisión sistemática de los Sistemas de Planificación de los países en mención, desde el marco jurídico que lo ampara hasta su metodología de trabajo.Como resultado se ha podido observar que Guatemala es el único país que tiene definido un sistema de planificación ascendente y que ha
\end{abstract}

\begin{abstract}
${ }^{1}$ En el marco del desarrollo de mis estudios de maestría en Prospectiva Estratégica para el Desarrollo Nacional en la Universidad Nacional Mayor de San Marcos UNMSM, se decidió evaluar los Sistemas de Planificación de los 4 países latinoamericanos mencionados en el título debido a que comparten un pasado histórico precolombino de alto desarrollo cultural y porque en la actualidad estos países tratan de revalorizar sus orígenes ancestrales considerando esta condición prioritaria en el momento de plantear la planificación de sus países. Este artículo es una revisión sistemática de los sistemas de planificación de dichos países.

${ }^{2}$ Ingeniero Informático, Pontificia Universidad Católica del Perú, Lima, Perú. estudios de magister en Prospectiva Estratégica para el Desarrollo Nacional, Universidad Nacional Mayor de San Marcos, Lima, Perú (Diciembre 2017). Especialización en Planeamiento Estratégico del Sector Público, Universidad del Pacifico, Lima, Perú. Miembro de la comisión de Prospectiva del Colegio de Ingenieros del Perú CD Lima. Colaborador de Organización Panamericana de la Salud en temas de e-Health. Ca. Los Auditores H-12, SJL, Lima 36. (51) 988662271. Correo Electrónico: sanchez.alvaro@pucp.pe
\end{abstract}

(C) Los autores. Este artículo es publicado por Pensamiento Crítico de la Facultad de Ciencias Económicas, Universidad Nacional Mayor de San Marcos. Este es un artículo de acceso abierto, distribuido bajo los términos de la licencia Creative Commons Atribucion - No Comercia_Compartir Igual 4.0 Internacional. (http:// creativecommons.org/licenses/by-nc-sa/4.0/) que permite el uso no comercial, distribución y reproducción en cualquier medio, siempre que la obra original sea debidamente citada. 
definido metodologías de trabajo prospectivo desde los más bajos niveles. También se ha podido determinar que todos los países evaluados excepto Perú hacen una revalorización explicita de lo ancestral o indígena.

Palabras Clave: Planificación para el Desarrollo; Prospectiva; Planeamiento Estratégico. Códigos JEL: 021, P11, P21, P41, R58.

\begin{abstract}
The current research make an exploration about some concepts linked to strategic planning of countries and comparison of the Planning Systems and their strategic development planning for Bolivia, Ecuador Guatemala and Peru.For that purpose, in the first part a systematic review of definitions was made and in the second part a systematic review of planning systems of said countries from the juridical framework that cover it up to its working methodology. Finally, as a result, it has been determined that Guatemala is the only country that has defined an upward planning system and uses the foresight working methodology from lowest levels. In addition, it has been possible to determine that all countries, except Peru, have made an explicit reassessment of the ancestral or indigenous question.
\end{abstract}

Keywords: Development Planning; Prospective; Foresight; Strategic Planning. JEL Classification Codes: 021, P11, P21, P41, R58.

\title{
1. Introducción
}

En 2012 el Instituto Latinoamericano y del Caribe de Planificación Económica y Social (ILPES) cumplía 50 años de trabajo dedicado al fortalecimiento de las instituciones y las competencias necesarias para una adecuada gestión pública y sobre todo la planificación que permita obtener Resultados de Desarrollo.

En el 2013, en Brasilia se produce la Decimocuarta reunión del Consejo Regional de Planificación del Instituto Latinoamericano y del Caribe de Planificación Económica y Social, la cual reúne a los ministros u otras autoridades responsables de la planificación en América Latina y el Caribe. En ella se plantea una planificación con características distintas, es más participativa, en búsqueda de un desarrollo integral y sostenible, con horizontes temporales de mediano y largo plazos, y sobre todo con énfasis en el progreso social, donde se impulsa mucho la participación ciudadana como en el caso de Guatemala.

El ILPES propugna una aproximación regional, a fin de construir una visión y un concepto de bloque regional que mejore las condiciones 
para impulsar el desarrollo, la integración y la cooperación regional. Se describen dimensiones del desarrollo que abarcan espacios multinacionales con un abordaje desde la planificación, que impulsa la integración y la cooperación.

La mayoría de las experiencias promueven una planificación renovada, y cuentan con características comunes: a) Mayor participación ciudadana, b) Implementación de la planificación en coordinación con niveles y sectores de gobierno, c) El monitoreo y la evaluación, y d) definición de visiones de país con horizontes de largo plazo que buscan reducir las brechas sociales (ILPES, 2013).

En este trabajo se busca hacer una evaluación de cuanto se ha avanzado respecto de los sistemas de planificación y la planificación para su desarrollo sostenible en modo comparativo en el Perú respecto de otros 3 países de Latinoamérica como son Bolivia, Ecuador y Guatemala.

Para ello se hace una revisión de algunos conceptos necesarios para comprender que implica una planificación para el desarrollo sostenible y un plan de desarrollo nacional. Seguidamente se hace una comparación de los sistemas de planificación de los cuatro (4) países considerando desde la base legal y filosofía que lo soporta, las organizaciones que integran sus respectivos sistemas, los niveles de poder y el plan de desarrollo de cada país.

Finalmente se harán algunas recomendaciones derivadas de las evaluaciones realizadas.

\section{Metodología}

Para este trabajo se hace una evaluación exploratoria de los conceptos relacionados a la Planificación para el Desarrollo Sostenible y los diferentes documentos, como normas y planes de las instituciones involucradas en los sistemas de Planificación de los países evaluados.

\section{Conceptos relacionados al Desarrollo Sostenible de un país.}

\subsection{Valor Público}

Tregoffi (2013), nos indica que se genera valor público cuando se atiende las demandas de los ciudadanos y sus representantes políticos; es decir, la sociedad civil puede tener demandas sociales y para expresarlas pueden 
designar un grupo de 'personas u organizaciones que las representen. Al ser atendidas dichas demandas por la gestión pública se genera valor 'público. Por otra parte, Gamarra et al (2015, p.20), precisan que:

“... se genera valor público a través de:

- Respuestas a problemas relevantes para los ciudadanos/usuarios

- La apertura de nuevas oportunidades para generaciones actuales y/o futuras

- Procesos que construyen comunidad, ciudadanía, democracia y capital social: deliberación, participación, entre otros".

De igual forma, López (2016) indica que, el Valor Público es una estrategia aplicada en la gestión pública y la conforman elementos de desarrollo, democracia y modernización.

En consecuencia se podría decir que, Valor Público es todo aquello que es generado por la administración pública para satisfacer una necesidad o demanda de la nación, reconocida por los administrados, es decir, una demanda de la sociedad civil.

\subsection{Planificación Estratégica}

Álvarez (2012), indica que la planificación Estratégica surge como una forma de interpretar y utilizar los datos obtenidos en las investigaciones sociales para generar plataformas estratégicas de trabajo que sean más eficaces, por otra parte, Burgwal y Cuellar (1999, p.25), precisaban "La Planificación Estratégica es una poderosa herramienta de diagnóstico, análisis, reflexión y toma de decisiones colectivas, acerca del que hacer actual y el camino que debe recorrer en el futuro las comunidades, organizaciones e instituciones".

Sainz de Vicuña (2015) nos dice que es el proceso reflexivo sistemático por el cual la alta dirección define la aplicación planificada de sus recursos para alcanzar los objetivos de la organización y Tassara (2014, p.3), nos refiere como concepto de CEPAL para Planificación Estratégica:

"una herramienta de gestión que permite apoyar la toma de decisiones de las organizaciones en torno al quehacer actual y al camino que deben recorrer en el futuro para adecuarse a los cambios y a las demandas que les impone el entorno y lograr la mayor eficiencia, eficacia, calidad en los bienes y servicios que se proveen; y consiste en, un ejercicio de formulación [...] de objetivos de carácter prioritario, cuya característica principal es el establecimiento de las [...] estrategias para alcanzar dichos objetivos. Desde esta perspectiva la planificación estratégica es una herramienta clave para la toma de decisiones de las instituciones públicas". 
Para Tassara, los Planes estratégicos pueden complementar el sistema de planificación subnacional con un enfoque territorial orientado a valorizar los aportes locales, sobre un horizonte temporal de diez a veinte años.

En consecuencia, podríamos indicar que Planificación Estratégica, es un proceso reflexivo y metódico por el cual la alta dirección define en el presente, la ruta de acciones a seguir para alcanzar los objetivos trazados. En el caso del sector público, la alta dirección estaría conformada por los líderes del poder ejecutivo y tendrían que considerar los aportes de todos los niveles de gobierno con el objeto de alcanzar los objetivos de generación de valor público.

\subsection{Planificación Prospectiva}

Mera (2014, p.14), haciendo referencia a Godet (2007), nos dice que: "planeamiento estratégico prospectivo como un nuevo enfoque de planeamiento que consiste en guiar a todos los planeamientos estratégicos de la organización hacia un futuro, creando escenarios futuros que desea alcanzar la organización, y tomando medidas correctivas para un presente más deseado y para alcanzar aquel escenario posible, deseable y probable" y Ramírez (2012), haciendo mención a una publicación de Godet del 2007, indica que la prospectiva es una herramienta de planificación de largo plazo que implementa un estudio para la anticipación del futuro, posibilitando la preparación a cambios posibles esperados.

Por otra parte, Lucena (2014), refiere al Planeamiento Prospectivo como una herramienta gerencial que permite tomar decisiones por medio del análisis de alternativas y opciones idóneas a los escenarios posibles, previendo las consecuencias y sin perder de vista los objetivos organizacionales y Rivera et al (2015, p.2), citando a una publicación de Rosales-Morales del 2010, indica que: "Planeación Prospectiva es el énfasis que hace en los futuros deseados y la búsqueda de los medios para alcanzarlos, considerando desde el planteamiento de los ideales tanto sociales como económicos, así como la forma en que deberán tomarse las decisiones individuales por parte de los involucrados en el proceso".

En consecuencia, podemos indicar entonces que, Planeamiento Prospectivo es la planificación estratégica orientada a alcanzar cualquier 
escenario de futuro que resulte de un estudio prospectivo y que se elija como apuesta para su consecución. Es decir, se desarrolla un plan estratégico que puede considerar variantes según cada escenario de futuro definido.

\subsection{Planificación para el Desarrollo Sostenible}

El antiguo Ministerio de Desarrollo Sostenible y Planificación de Bolivia en 1996 (MDS 2016, p.3), indicaba que: "la planificación del Desarrollo Sostenible es un proceso de interacción entre el Estado y la Sociedad, que se desarrolla dentro de un espacio geográfico determinado y está orientada a articular las políticas de Estado con las prioridades gubernamentales para administrar los recursos públicos en la perspectiva de alcanzar el desarrollo sostenible", mientras que, CEPAL (2011, p.51), indica que: "La planificación para el desarrollo (...) es un proceso gubernamental integrador, explícito, organizado y participativo, orientado a determinar los cursos de acción que un país debe emprender para la consecución de sus objetivos de largo plazo".

Por otra parte, Naser y Conche (2014), sostienen que la Planificación para el Desarrollo Sostenible constituye un instrumento para conducir el proceso de transformación de la gestión pública y de la sociedad sujeta a un esquema de concertación nacional y de alianzas público-privadas y debe reorientarse hacia la búsqueda de provisión de las demandas de los ciudadanos y CEPAL en otra publicación (2015), describe la Planificación para el Desarrollo Sostenible, como aquella para hacer frente a los desafíos de la integración de las tres dimensiones del desarrollo sostenible, el cambio estructural y la desigualdad. Definiendo las tres dimensiones como: Inclusión Social, Inclusión Económica e Inclusión Ambiental.

En consecuencia, se puede decir que, la Planificación para el Desarrollo Sostenible, es aquella que permite implementar un plan de Desarrollo Nacional para alcanzar objetivos de desarrollo en los 3 niveles: Social, Económico y Ecológico, teniendo en consideración a la generación de valor público.

\subsection{Plan de Desarrollo Nacional}

La Dirección Nacional de Planeamiento de Colombia (2016), describe al Plan de Desarrollo Nacional como el documento que sirve de base y provee los lineamientos estratégicos de las políticas públicas 
formuladas por el Presidente de la República a través de su equipo de Gobierno, mientras que para la Secretaria de Hacienda y Crédito Público de México en su "Plan Nacional de Desarrollo 2013-2018”(SHCP, 2013), es un documento de trabajo que rige la programación de toda la administración y el cual, ha sido producto del ejercicio reflexivo de la sociedad civil sobre los retos y oportunidades que el país enfrenta. Expone la ruta que el Gobierno de la República se ha trazado para contribuir de manera más eficaz a que todos juntos puedan lograr que México alcance su máximo potencial.

Por otra parte, el Consejo Nacional de Desarrollo Urbano y Rural de Guatemala - CONADUR, considera que, el Plan Nacional de Desarrollo, es un instrumento técnico de orientación de la gestión pública, que articula la decisión política al más alto nivel y la acción estratégica del Estado en función del desarrollo (Katún, 2014) y el Centro Nacional de Planeamiento Estratégico de Perú - CEPLAN, reconoce: "El Plan Bicentenario: El Perú hacia el 2021 es un plan de largo plazo que contiene las políticas nacionales de desarrollo que deberá seguir el Perú en los próximos diez años.". El mismo, permite la priorización de los proyectos de inversión del estado. (CEPLAN 2011, p.22).

Finamente, podríamos indicar que un Plan de Desarrollo Nacional es un documento de Planificación Estratégica, pudiendo ser prospectivo, producto de la reflexión sistemática y consensuada de los diferentes actores de una nación. El cual define, las directrices que debe de seguir la política pública de una nación con el objeto de generar Desarrollo Sostenible y en correspondencia valor público para su nación.

\subsection{Plan de Ordenamiento Territorial.}

Para Vergara (2016), el Plan de Ordenamiento Territorial (POT) es el mecanismo básico del planeamiento físico-jurídico-económico del territorio y tiene tres componentes: general, urbano y rural. Define los usos del suelo y las dotaciones físicas de los gobiernos locales, mientras 
que Reyna et al (2014), haciendo referencia a Moreno M. indican que, el Ordenamiento Territorial (OT) es un instrumento de planificación, gestión y construcción colectiva, aplicable al desarrollo sostenible de un país o región. Utiliza conocimientos científicos de diseño técnico y de gestión territorial, orientados a conseguir un Desarrollo Sostenible.

Por otra parte, la norma 777 de Bolivia, sobre Ordenamiento Territorial, indicaba que: el Plan de Ordenamiento Territorial es un instrumento de carácter normativo, técnico - político y administrativo para la gestión del territorio mediante el cual se planifica y regula el uso del suelo y se optimiza las modalidades de su ocupación y Para el Ministerio de Ambiente de Perú, El Plan de Ordenamiento Territorial, "es un instrumento técnico sustentatorio orientador de la planificación y gestión del territorio, que promueve la ocupación del territorio garantizando el derecho de toda persona a un ambiente saludable, y el aprovechamiento sostenible de los recursos naturales, articulando los planes ambientales, de desarrollo económico, social, cultural y otras políticas de desarrollo vigentes en el país".

En consecuencia, se puede indicar que un Plan de Ordenamiento Territorial, es un instrumento de planificación estratégica, político y económico, que permite optimizar el uso y explotación sostenible de los suelos de una región o nación con el objeto de impulsar su Desarrollo Sostenible.

\section{Evaluación comparativa de los Sistemas de Planificación para el Desarrollo Sostenible en los 4 países.}

La evaluación comparativa se ha dividido en 3 partes:

\subsection{Base legal y filosofía que soporta su planificación}

Los cuatro (4) países evaluados han desarrollado su planificación en el marco de sus respectivas Constituciones políticas, y excepto Ecuador, en un Acuerdo de intenciones de los principales actores de la sociedad. En la Tabla 1: "Comparación de las constituciones políticas de los países evaluados", que se puede encontrar en el anexo del artículo, podemos observar que las cartas magnas de Bolivia y Guatemala, presentan reivindicaciones, tienen un lineamiento definido y enmarcan el Planeamiento Estratégico de los países, no así las constituciones de Ecuador y Perú. 
Pensamiento Crítico Vol. 22. $\mathrm{N}^{\circ} 2$

Tabla 1.

Comparación de las constituciones políticas de los países evaluados

\begin{tabular}{|c|c|c|c|c|}
\hline & \multicolumn{4}{|c|}{ Países Evaluados } \\
\hline & Bolivia & Ecuador & Guatemala & Perú \\
\hline $\begin{array}{l}\text { Fecha de } \\
\text { promulgación }\end{array}$ & $\begin{array}{c}09 \text { de febrero del } \\
2009\end{array}$ & $\begin{array}{c}08 \text { de junio del } \\
1998\end{array}$ & $\begin{array}{c}14 \text { de enero de } \\
1986\end{array}$ & $\begin{array}{c}29 \text { de diciembre de } \\
1993\end{array}$ \\
\hline Reivindicaciones & $\begin{array}{l}\text { La revalorización } \\
\text { de las poblaciones } \\
\text { indígenas y } \\
\text { campesinas así } \\
\text { como su cultura } \\
\text { y sus principios } \\
\text { ancestrales para } \\
\text { "Vivir bien". }\end{array}$ & $\begin{array}{l}\text { No hay } \\
\text { reivindicaciones. } \\
\text { El artículo } \\
243.1 \text { plantea } \\
\text { el desarrollo } \\
\text { socialmente } \\
\text { equitativo, } \\
\text { regionalmente } \\
\text { equilibrado, } \\
\text { ambientalmente } \\
\text { sustentable y } \\
\text { democráticamente } \\
\text { participativo. }\end{array}$ & $\begin{array}{l}\text { No hay } \\
\text { reivindicaciones. } \\
\text { La sección tercera } \\
\text { del capítulo uno, } \\
\text { en el artículo } 66 \\
\text { y 67, reconoce la } \\
\text { pluriculturalidad, } \\
\text { sus diferentes } \\
\text { costumbres y } \\
\text { organizaciones } \\
\text { sociales, y, la } \\
\text { protección de } \\
\text { la tierra de los } \\
\text { mismos. }\end{array}$ & $\begin{array}{l}\text { No hay } \\
\text { reivindicaciones, } \\
\text { se reconocen a } \\
\text { las comunidades } \\
\text { nativas y su } \\
\text { identidad cultural } \\
\text { así como a las } \\
\text { comunidades } \\
\text { campesinas. }\end{array}$ \\
\hline $\begin{array}{l}\text { Respecto a la } \\
\text { Planificación del } \\
\text { país }\end{array}$ & $\begin{array}{l}\text { Establece la } \\
\text { participación de } \\
\text { los diferentes } \\
\text { niveles de gobierno } \\
\text { incluido la } \\
\text { sociedad civil. }\end{array}$ & $\begin{array}{l}\text { Establece la } \\
\text { orientación } \\
\text { participativa y } \\
\text { liderada por el } \\
\text { presidente de la } \\
\text { república. }\end{array}$ & $\begin{array}{l}\text { Crea el Consejo } \\
\text { Nacional de } \\
\text { Desarrollo Urbano } \\
\text { y Rural coordinado } \\
\text { por el presidente } \\
\text { de la república } \\
\text { y los Consejos } \\
\text { Regionales } \\
\text { de Desarrollo } \\
\text { Urbano y Rural } \\
\text { presididos por un } \\
\text { representante del } \\
\text { presidente de la } \\
\text { república. }\end{array}$ & $\begin{array}{l}\text { Sin lineamientos. } \\
\text { El art. } 192 \text { indica } \\
\text { que los gobiernos } \\
\text { regionales deben } \\
\text { de fomentar } \\
\text { el desarrollo } \\
\text { en función a la } \\
\text { planificación para } \\
\text { el desarrollo del } \\
\text { país. }\end{array}$ \\
\hline $\begin{array}{l}\text { Otras } \\
\text { consideraciones }\end{array}$ & $\begin{array}{l}\text { Hace explicito } \\
\text { su modelo de } \\
\text { planificación, } \\
\text { considerándola } \\
\text { en la misma } \\
\text { y haciendo la } \\
\text { revalorización } \\
\text { de su cultura } \\
\text { ancestral para } \\
\text { "Vivir bien". }\end{array}$ & $\begin{array}{l}\text { Establece que el } \\
\text { sistema nacional } \\
\text { de planificación } \\
\text { está a cargo de } \\
\text { un organismo } \\
\text { dependiente de la } \\
\text { presidencia. }\end{array}$ & $\begin{array}{l}\text { El Consejo Nacional } \\
\text { de Desarrollo } \\
\text { Urbano y Rural } \\
\text { tendrá a su cargo } \\
\text { la formulación } \\
\text { de las políticas } \\
\text { de desarrollo } \\
\text { urbano y rural, } \\
\text { así como las de } \\
\text { ordenamiento } \\
\text { territorial. }\end{array}$ & $\begin{array}{l}\text { Se define una } \\
\text { economía social de } \\
\text { mercado. }\end{array}$ \\
\hline
\end{tabular}

Fuente: Elaboración propia en base a las constituciones de cada país 
En la Tabla 2: "Comparación de los Acuerdos Previos a la implementación de los Sistemas de Planificación" que también es ubicable en el anexo del artículo, se observa que todos los países excepto Ecuador han firmado un acuerdo de la sociedad civil como parte del proceso previo a la planificación de desarrollo de su respectiva nación, presentando en ello las expectativas de cada nación según su propia coyuntura.

Tabla 2.

Comparación de los Acuerdos Previos a la implementación de los Sistemas de Planificación

\begin{tabular}{|c|c|c|c|c|}
\hline \multirow[b]{2}{*}{. } & \multicolumn{4}{|c|}{ Países Evaluados } \\
\hline & Bolivia & Ecuador & Guatemala & Perú \\
\hline $\begin{array}{l}\text { Año de firma de } \\
\text { acuerdo }\end{array}$ & 2013 & $\begin{array}{l}\text { Sin información de } \\
\text { acuerdo previo }\end{array}$ & $\begin{array}{c}29 \text { de diciembre } \\
1996\end{array}$ & $\begin{array}{l}05 \text { de marzo del } \\
2002\end{array}$ \\
\hline $\begin{array}{l}\text { Nombre del } \\
\text { acuerdo }\end{array}$ & $\begin{array}{l}\text { La agenda } \\
\text { patriótica al } \\
\text { Bicentenario de } \\
\text { Bolivia } 2025 \text {. }\end{array}$ & 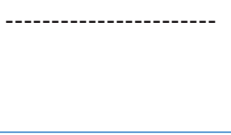 & $\begin{array}{l}\text { El acuerdo de Paz } \\
\text { Firme y Duradera. }\end{array}$ & Acuerdo Nacional. \\
\hline Objetivos & $\begin{array}{l}\text { Alcanzar la } \\
\text { independencia } \\
\text { en el desarrollo } \\
\text { de Bolivia con } \\
\text { reconocimientos } \\
\text { de su cultura } \\
\text { ancestral en base a } \\
13 \text { pilares. }\end{array}$ & - & $\begin{array}{l}\text { Reafirmar todos } \\
\text { los acuerdos de } \\
\text { paz previamente } \\
\text { firmados bajo los } \\
\text { ejes: } \\
\text { 1.- Eje de } \\
\text { reasentamiento, } \\
\text { incorporación } \\
\text { de la Unidad } \\
\text { Revolucionaria } \\
\text { Nacional } \\
\text { Guatemalteca } \\
\text { URNG y } \\
\text { reconciliación } \\
\text { nacional. } \\
\text { 2.- Eje de } \\
\text { desarrollo } \\
\text { productivo } \\
\text { sostenible. } \\
\text { 3.-Eje de } \\
\text { modernización } \\
\text { del Estado } \\
\text { democrático, } \\
\text { incluyendo el } \\
\text { fortalecimiento } \\
\text { de las capacidades } \\
\text { de participación } \\
\text { y concertación } \\
\text { de las distintas } \\
\text { expresiones de la } \\
\text { sociedad civil. }\end{array}$ & $\begin{array}{l}\text { Establece } 4 \\
\text { grandes objetivos: } \\
\text { 1.- Fortalecimiento } \\
\text { de la Democracia y } \\
\text { Estado de Derecho. } \\
\text { 2.-Desarrollo con } \\
\text { Equidad y Justicia } \\
\text { Social. } \\
\text { 3.-Promoción de } \\
\text { la Competitividad } \\
\text { del País. } \\
\text { 4.-Afirmación } \\
\text { de un Estado } \\
\text { Eficiente, } \\
\text { Transparente y } \\
\text { Descentralizado. }\end{array}$ \\
\hline
\end{tabular}

Fuente: Elaboración propia en base a la revisión de los documentos previos que sirvieron de base a la planificación de cada país evaluado 


\subsection{La organización de los Sistemas de Planificación en cada país y su nivel de poder en la estructura de gobierno.}

Diferentes estados han tenido diferentes formas de crear sus Sistemas de Planificación, la mayoría de ellos por normativa emitida por su respectivo parlamento y en general son bastante jóvenes, datando el más longevo el de Perú creado en el año 2008. Se tiene que precisar que sólo el sistema de planificación de Bolivia tiene en sus objetivos definidos los plazos para la planificación, siendo estos de 5 años y 25 años. Esta información se puede observar en la Tabla 3: "Comparación de los Sistemas Nacionales de Planificación de los países evaluados", la misma que por espacio se ha colocado igualmente en el anexo correspondiente.

En cuanto a la composición de los sistemas de Planificación se debe indicar que Bolivia y Perú presentan esquemas que integran únicamente organismos públicos, mientras que Ecuador y Guatemala tienen un modelo basado en diferentes tipos y niveles de Consejos, los cuales se encargan de evaluar las respectivas propuestas. Cabe destacar que el modelo de Guatemala implica una Planificación de Abajo hacia Arriba es decir es ascendente, y el resto de países evaluados presenta un sistema vertical de arriba hacia abajo. Mayor información de las comparaciones se puede encontrar en la Tabla 4: "Comparación de la composición y forma de trabajo de los Sistemas Nacionales de Planificación de los países evaluados” en el anexo correspondiente.

Respecto de las instituciones que tienen la responsabilidad de dirigir la planificación para el desarrollo en cada país se debe indicar que algunas son anteriores a los últimos sistemas de planificación de cada país, el caso más relevante es el de Guatemala que fue creada en 1997 y la última en crearse ha sido el CEPLAN de Perú en el 2008. Algo que se debe destacar es que el SENPLADES de Ecuador tiene precisado dentro de sus objetivos la orientación de la inversión públicahacia los objetivos y metas de su Planificación Nacional y la única institución que desde sus objetivos está dirigida a hacer Ordenamiento Territorial es el Ministerio de Planificación del Desarrollo de Bolivia. Mayor referencia en la Tabla 5: "Comparación de las entidades responsables de la planificación de cada país" también ubicable en el anexo del artículo. 
Tabla 3.

Comparación de los Sistemas Nacionales de Planificación de los países evaluados.

\begin{tabular}{|c|c|c|c|c|}
\hline & \multicolumn{4}{|c|}{ Países Evaluados } \\
\hline & Bolivia & Ecuador & Guatemala & Perú \\
\hline $\begin{array}{l}\text { Año de } \\
\text { creación }\end{array}$ & $\begin{array}{l}\text { Se implementa } \\
\text { con la ley } 777 \\
\text { de la Asamblea } \\
\text { Constituyente el } \\
\text { año } 2016\end{array}$ & $\begin{array}{l}\text { Se definen sus } \\
\text { responsabilidades } \\
\text { con el Decreto } \\
\text { ejecutivo } 1577 \text { del } \\
26 \text { de febrero del } \\
2009 .\end{array}$ & $\begin{array}{l}\text { Decreto número } \\
11 \text { del Congreso } \\
\text { de la Republica } \\
\text { del } 12 \text { de marzo } \\
\text { del } 2012 .\end{array}$ & $\begin{array}{l}\text { Decreto legislativo } 1088 \\
\text { del } 27 \text { de junio del } 2008\end{array}$ \\
\hline Denominación & $\begin{array}{l}\text { Sistema de } \\
\text { Planificación } \\
\text { Integral del } \\
\text { Estado-SPIE. }\end{array}$ & \begin{tabular}{|l|} 
El Sistema \\
Nacional \\
Descentralizado \\
de Planificación \\
Participativa \\
-SNDPP. \\
\end{tabular} & $\begin{array}{l}\text { Sistema de } \\
\text { Consejos de } \\
\text { Desarrollo- } \\
\text { SISCODE. }\end{array}$ & $\begin{array}{l}\text { Sistema Nacional de } \\
\text { Planeamiento Estratégico } \\
\text { (SINAPLAN). }\end{array}$ \\
\hline Objetivos & $\begin{array}{l}\text { 1.- Formular el } \\
\text { Plan General } \\
\text { de Desarrollo } \\
\text { Económico y } \\
\text { Social PGDES } \\
\text { (25 años) y } \\
\text { el Plan de } \\
\text { Desarrollo } \\
\text { Económico y } \\
\text { Social PDES (5 } \\
\text { años). } \\
\text { 2.-Coordinar } \\
\text { la formulación, } \\
\text { ejecución, } \\
\text { implementación, } \\
\text { seguimiento, } \\
\text { evaluación } \\
\text { y ajustes del } \\
\text { PGDES y PDES. }\end{array}$ & $\begin{array}{l}\text { 1.-Contribuir al } \\
\text { cumplimiento } \\
\text { progresivo de } \\
\text { los derechos } \\
\text { constitucionales, } \\
\text { los objetivos } \\
\text { del régimen de } \\
\text { desarrollo y } \\
\text { disposiciones del } \\
\text { régimen del buen } \\
\text { vivir. } \\
\text { 2.-Generar los } \\
\text { mecanismos e } \\
\text { instancias de } \\
\text { coordinación de } \\
\text { la planificación } \\
\text { y de la política } \\
\text { pública en todos } \\
\text { los niveles de } \\
\text { gobierno. } \\
\text { 3.-Orientar la } \\
\text { gestión pública } \\
\text { hacia el logro } \\
\text { de resultados, } \\
\text { que contemple } \\
\text { los impactos } \\
\text { tangibles e } \\
\text { intangibles. }\end{array}$ & $\begin{array}{l}\text { Organizar y } \\
\text { coordinar la } \\
\text { administración } \\
\text { pública mediante } \\
\text { la formulación } \\
\text { de políticas de } \\
\text { desarrollo, planes } \\
\text { y programas } \\
\text { presupuestarios } \\
\text { y el impulso de } \\
\text { la coordinación } \\
\text { interinstitucional, } \\
\text { pública y privada. }\end{array}$ & $\begin{array}{l}\text { 1.-Orientar y definir } \\
\text { metodología para } \\
\text { articular e integrar la } \\
\text { elaboración de Plan } \\
\text { Estratégico de Desarrollo } \\
\text { Nacional y otros planes } \\
\text { nacionales. } \\
\text { 2.-Promover y articular } \\
\text { el fortalecimiento de } \\
\text { capacidades para el } \\
\text { planeamiento estratégico. } \\
\text { 3.-Desarrollar el } \\
\text { seguimiento de la gestión } \\
\text { para resultados de } \\
\text { mediano y largo plazo. } \\
\text { 4.-Promover la } \\
\text { cooperación y acuerdos } \\
\text { entre los sectores } \\
\text { públicos y privados en el } \\
\text { proceso de formulación } \\
\text { de los planes estratégicos. } \\
\text { 5.-Promover el } \\
\text { Planeamiento Estratégico } \\
\text { y sus sub instrumentos } \\
\text { con una visión } \\
\text { prospectiva de medio y } \\
\text { largo plazo. } \\
\text { 6.-Determinar la visión } \\
\text { de futuro compartida, } \\
\text { concertada y de los } \\
\text { objetivos y planes } \\
\text { estratégicos." }\end{array}$ \\
\hline
\end{tabular}

Fuente: Elaboración propia en base a la revisión de los documentos que generan los Sistemas de Planificación de cada país evaluado 
Tabla 4.

Comparación de la composición y forma de trabajo de los Sistemas Nacionales de Planificación de los países evaluados

\begin{tabular}{|c|c|c|c|c|}
\hline & \multicolumn{4}{|c|}{ Países Evaluados } \\
\hline & Bolivia & Ecuador & Guatemala & Perú \\
\hline Composición & $\begin{array}{l}\text { a. Órgano } \\
\text { Legislativo } \\
\text { b. Órgano Ejecutivo, } \\
\text { c. Órgano Judicial, } \\
\text { d. Órgano Electoral, } \\
\text { e. Tribunal } \\
\text { Constitucional } \\
\text { Plurinacional, } \\
\text { f. Instituciones de } \\
\text { Control y Defensa } \\
\text { de la Sociedad y del } \\
\text { Estado, } \\
\text { g. Entidades } \\
\text { Territoriales } \\
\text { Autónomas, } \\
\text { h. Empresas } \\
\text { Públicas, } \\
\text { i. Universidades } \\
\text { Públicas }\end{array}$ & $\begin{array}{l}\text { a. El Consejo } \\
\text { Nacional de } \\
\text { Planificación; } \\
\text { b. La Secretaría } \\
\text { Técnica del Sistema } \\
\text { SENPLADES; } \\
\text { c. Los Consejos } \\
\text { de Planificación } \\
\text { de los Gobiernos } \\
\text { Autónomos } \\
\text { Descentralizados; } \\
\text { d. Los Consejos } \\
\text { Sectoriales de } \\
\text { Política Pública de la } \\
\text { Función Ejecutiva; } \\
\text { e. Los Consejos } \\
\text { Nacionales de } \\
\text { Igualdad. } \\
\text { f. Las instancias } \\
\text { de participación } \\
\text { definidas en la } \\
\text { Constitución de la } \\
\text { República y la Ley }\end{array}$ & $\begin{array}{l}\text { Lo comprenden } \\
\text { los consejos de } \\
\text { desarrollo Urbano y } \\
\text { Rural en } 5 \text { niveles: } \\
\text { a. El nacional, con } \\
\text { el Consejo Nacional } \\
\text { de Desarrollo } \\
\text { Urbano y Rural. } \\
\text { b. El regional, } \\
\text { con los Consejos } \\
\text { Regionales de } \\
\text { Desarrollo Urbano } \\
\text { y Rural. } \\
\text { c. El } \\
\text { departamental, } \\
\text { con los Consejos } \\
\text { Departamentales de } \\
\text { Desarrollo. } \\
\text { d. El municipal, } \\
\text { con los Consejos } \\
\text { Municipales de } \\
\text { Desarrollo. } \\
\text { e. El comunitario, } \\
\text { con los Consejos } \\
\text { Comunitarios de } \\
\text { Desarrollo. }\end{array}$ & $\begin{array}{l}\text { a. El poder } \\
\text { ejecutivo: } 19 \\
\text { ministerios y } 73 \\
\text { entidades públicas. } \\
\text { b. El poder } \\
\text { legislativo } \\
\text { representado en } \\
\text { el congreso de la } \\
\text { república } \\
\text { c. El poder judicial: } \\
\text { la academia de la } \\
\text { magistratura, los } \\
55 \text { Organismos } \\
\text { Constitucionales } \\
\text { Autónomos (OCA) } \\
\text { que incluyen a } \\
\text { las universidades } \\
\text { públicas. } \\
\text { d. Los gobiernos } \\
\text { sub nacionales: } \\
26 \text { gobiernos } \\
\text { regionales y 1,864 } \\
\text { gobiernos locales. } \\
\text { e. El foro del } \\
\text { Acuerdo Nacional. }\end{array}$ \\
\hline $\begin{array}{l}\text { Modelo de } \\
\text { articulación }\end{array}$ & $\begin{array}{l}\text { El SPIE está } \\
\text { compuesto por } 3 \\
\text { sub sistemas: } \\
\text { a. Planificación. } \\
\text { b. Inversión Pública } \\
\text { y Financiamiento } \\
\text { Externo para el } \\
\text { Desarrollo Integral. } \\
\text { c. Seguimiento y } \\
\text { Evaluación Integral } \\
\text { de Planes. } \\
\text { Los gobiernos sub- } \\
\text { nacionales articulan } \\
\text { directamente } \\
\text { con los sectores } \\
\text { de acuerdo a la } \\
\text { temática. }\end{array}$ & $\begin{array}{l}\text { Se articula de } \\
\text { forma vertical } \\
\text { por sectores con } \\
\text { activa participación } \\
\text { ciudadana en los } \\
\text { diferentes niveles. }\end{array}$ & $\begin{array}{l}\text { En teoría de forma } \\
\text { ascendente. Desde } \\
\text { las comunidades } \\
\text { hacia el gobierno } \\
\text { central. }\end{array}$ & $\begin{array}{l}\text { La articulación } \\
\text { se da de forma } \\
\text { vertical siendo } \\
\text { liderado por los } \\
\text { sectores. Los } \\
\text { planes de los } \\
\text { diferentes niveles } \\
\text { están sujetos al } \\
\text { plan del sector. }\end{array}$ \\
\hline
\end{tabular}




\begin{tabular}{|c|c|c|c|c|}
\hline & Bolivia & Ecuador & Guatemala & Perú \\
\hline $\begin{array}{l}\text { Metodología } \\
\text { de trabajo. }\end{array}$ & $\begin{array}{l}\text { Cuentan con } 6 \\
\text { lineamientos } \\
\text { metodológicos } \\
\text { para planificación } \\
\text { que complementan } \\
\text { y articulan lo } \\
\text { definido en el PDES } \\
\text { con los sectores y } \\
\text { los gobiernos sub- } \\
\text { nacionales. }\end{array}$ & $\begin{array}{l}\text { Articulación } \\
\text { vertical con } \\
\text { participación de la } \\
\text { sociedad civil en } \\
\text { mesas de dialogo } \\
\text { en todos los } \\
\text { niveles. }\end{array}$ & $\begin{array}{l}\text { Los consejos de } \\
\text { Desarrollo del } \\
\text { más bajo nivel } \\
\text { proponen las } \\
\text { problemáticas a } \\
\text { tratary las elevan } \\
\text { al nivel superior } \\
\text { hasta llegar al } \\
\text { Consejo Nacional } \\
\text { de Desarrollo } \\
\text { Urbano y Rural. }\end{array}$ & $\begin{array}{l}\text { El CEPLAN } \\
\text { órgano rector del } \\
\text { Sistema Nacional } \\
\text { de Planificación } \\
\text { ha definido } \\
\text { metodologías para } \\
\text { la planificación } \\
\text { en los diferentes } \\
\text { niveles de } \\
\text { gobierno, están } \\
\text { articuladas } \\
\text { en forma } \\
\text { descendente y } \\
\text { liderada por los } \\
\text { sectores. }\end{array}$ \\
\hline $\begin{array}{l}\text { Nota: } \\
\text { Ultimas } \\
\text { correcciones } \\
\text { en el } \\
\text { Sistema de } \\
\text { Planificación } \\
\text { del Perú }\end{array}$ & \multicolumn{4}{|c|}{$\begin{array}{l}\text { El } 03 \text { de mayo del } 2017 \text { el CEPLAN emitió la directiva 001-2017-CEPLAN/ } \\
\text { PCDactualización a las directivasN } 001-2009 \text {-CEPLAN/PCD y N 001-2014-CEPLAN/ } \\
\text { PCD, y, el } 03 \text { de junio del } 2017 \text { la resolución N N 033-2017/CEPLAN/PCD dejando } \\
\text { de ser obligatorio el Planeamiento Prospectivo para las instituciones del estado, } \\
\text { como originalmente se exigía en la directiva N }{ }^{\circ} 001-2009 \text {-CEPLAN/PCD. Ante la } \\
\text { incapacidad del estado de hacer cumplir la directivas del 2009 y } 2014 \text { que exigía } \\
\text { todas las instituciones del estado deberían contar con Planificación Prospectiva en } \\
\text { un plazo que vencía el año } 2017 \text { el CEPLAN ha optado por derogar la exigencia de la } \\
\text { norma. }\end{array}$} \\
\hline
\end{tabular}

Fuente: Elaboración propia en base a la revisión de los documentos que generan los Sistemas de Planificación de cada país evaluado

\section{Tabla 5.}

Comparación de las entidades responsables de la planificación de cada país

\begin{tabular}{|c|c|c|c|c|}
\hline & \multirow{2}{*}{\multicolumn{4}{|c|}{ Países Evaluados }} \\
\hline & & & & \\
\hline & Bolivia & Ecuador & Guatemala & Perú \\
\hline $\begin{array}{l}\text { Fecha de } \\
\text { creación }\end{array}$ & Febrero del 2006 & $\begin{array}{l}\text { Se crea el } 20 \text { de } \\
\text { febrero del } 2004 \text { con } \\
\text { el Decreto Ejecutivo } \\
\text { No. } 1372\end{array}$ & $\begin{array}{l}\text { Creada mediante } \\
\text { el Decreto } 114 \text { del } \\
13 \text { de noviembre de } \\
1997 .\end{array}$ & $\begin{array}{l}\text { Al mismo tiempo } \\
\text { que el SINAPLAN. } \\
\text { Decreto legislativo } \\
1088 \text { del } 27 \text { de junio } \\
\text { del } 2008 .\end{array}$ \\
\hline $\begin{array}{l}\text { Nombre } \\
\text { de la } \\
\text { Institución }\end{array}$ & $\begin{array}{l}\text { Ministerio de } \\
\text { Planificación del } \\
\text { Desarrollo-MPD }\end{array}$ & $\begin{array}{l}\text { Secretaria Nacional } \\
\text { de Planificación } \\
\text { y Desarrollo- } \\
\text { SENPLADES }\end{array}$ & $\begin{array}{l}\text { Secretaría de } \\
\text { Planificación y } \\
\text { Programación de } \\
\text { la Presidencia - } \\
\text { SEGEPLAN }\end{array}$ & $\begin{array}{l}\text { Centro Nacional } \\
\text { de Planeamiento } \\
\text { Estratégico CEPLAN }\end{array}$ \\
\hline
\end{tabular}


Pensamiento Crítico Vol. 22. $\mathrm{N}^{\circ} 2$

\begin{tabular}{|c|c|c|c|c|}
\hline & Bolivia & Ecuador & Guatemala & Perú \\
\hline $\begin{array}{l}\text { Objetivos } \\
\text { de la } \\
\text { Institución }\end{array}$ & $\begin{array}{l}\text { El MPD formula } \\
\text { las políticas de } \\
\text { planificación, de } \\
\text { ordenamiento } \\
\text { territorial e } \\
\text { intersectoriales } \\
\text { principalmente en el } \\
\text { ámbito económico y } \\
\text { social. }\end{array}$ & $\begin{array}{l}\text { - Administrar } \\
\text { y coordinar el } \\
\text { Sistema Nacional } \\
\text { Descentralizado } \\
\text { de Planificación } \\
\text { Participativa para } \\
\text { la planificación del } \\
\text { desarrollo del país. } \\
\text { - Orientar la } \\
\text { inversión pública } \\
\text { hacia los objetivos y } \\
\text { metas establecidos } \\
\text { en la planificación. } \\
\text { - Realizar procesos } \\
\text { de monitoreo, } \\
\text { seguimiento y } \\
\text { evaluación. } \\
\text { - Promover los } \\
\text { procesos de } \\
\text { consolidación de la } \\
\text { institucionalidad } \\
\text { estatal, hacia una } \\
\text { gestión pública } \\
\text { transparente, } \\
\text { eficiente y } \\
\text { participativa. }\end{array}$ & $\begin{array}{l}\text { Asesorar y asistir } \\
\text { técnicamente a } \\
\text { las instituciones } \\
\text { públicas y al Sistema } \\
\text { de Consejos de } \\
\text { Desarrollo-SICODE, } \\
\text { para vincular } \\
\text { los procesos de } \\
\text { políticas públicas, } \\
\text { planificación y } \\
\text { programación } \\
\text { con el plan y la } \\
\text { política Nacional } \\
\text { de Desarrollo, así } \\
\text { como su debido } \\
\text { seguimiento y } \\
\text { evaluación. } \\
\text { Se convierte en } \\
\text { la secretaría del } \\
\text { Consejo Nacional de } \\
\text { desarrollo Urbano } \\
\text { y rural. }\end{array}$ & $\begin{array}{l}\text { - Actualización del } \\
\text { Plan de Desarrollo } \\
\text { Nacional - plan } \\
\text { bicentenario } 2021 . \\
\text { Articular la } \\
\text { planificación para } \\
\text { el Desarrollo a } \\
\text { nivel nacional en } \\
\text { función del Plan de } \\
\text { Desarrollo Nacional } \\
\text { al 2021. } \\
\text { - Seguimiento } \\
\text { y evaluación de } \\
\text { los planes de } \\
\text { Desarrollo. }\end{array}$ \\
\hline $\begin{array}{l}\text { Nivel de } \\
\text { Influencia } \\
\text { en la } \\
\text { Jerarquía } \\
\text { Pública. }\end{array}$ & $\begin{array}{l}\text { Es un Ministerio que } \\
\text { articula a alto nivel. }\end{array}$ & $\begin{array}{l}\text { Es una secretaría } \\
\text { dependiente de } \\
\text { la presidencia. } \\
\text { Coordina } \\
\text { directamente con } \\
\text { el presidente de la } \\
\text { república. }\end{array}$ & $\begin{array}{l}\text { Es una secretaría } \\
\text { dependiente de } \\
\text { la presidencia. } \\
\text { Coordina } \\
\text { directamente con } \\
\text { el presidente de la } \\
\text { república. }\end{array}$ & $\begin{array}{l}\text { Órgano del } \\
\text { ministerio de } \\
\text { la presidencia. } \\
\text { Coordina con } \\
\text { el ministro de } \\
\text { la presidencia, } \\
\text { sin alcanzar a } \\
\text { ser considerado } \\
\text { vinculante ante } \\
\text { las decisiones de } \\
\text { gobierno. }\end{array}$ \\
\hline
\end{tabular}

Fuente: Elaboración propia en base a la revisión de las normas de creación de cada Institución

El Gráfico 1 nos muestra el nivel de influencia que tiene cada institución dentro del organigrama del poder ejecutivo común a los 4 países evaluados, así podemos observar que el SENPLADES de Ecuador y el SEGEPLAN DE Guatemala son las instituciones que cuentan con mayor nivel de influencia en la planificación de sus respectivos países por cuanto actúan como órganos asesores de la presidencia. En Bolivia es un ministerio el encargado de la planificación y en Perú una simple 
institución adscrita aun ministerio, lo que la hace tener poca influencia vinculante en la planificación del país.

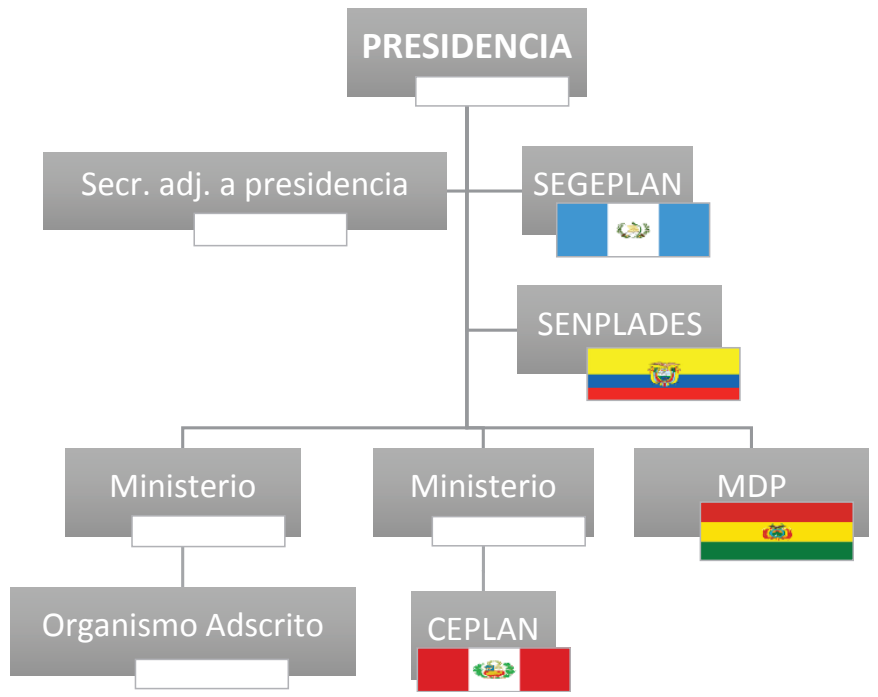

Gráfico 1. Nivel de influencia de los organismos encargados de desarrollar los planes estratégicos en los cuatro países

Fuente: Desarrollo Propio en base a la información que ofrecen las diferentes instituciones.

Finalmente, debemos indicar que la incapacidad del estado peruano para hacer cumplir las directivas 001 de los años 2009 y 2014 del CEPLAN en el término relacionado a la exigencia de que todas las instituciones del estado deberían contar con un Planeamiento Prospectivo en un plazo no mayor al 2017 los ha llevado a derogar tales normas para pasar de la exigencia a ser una potestad de la institución.

\section{Perú \\ 4.3. Los Planes de Desarrollo: Bolivia, Ecuador, Guatemala y}

Los Planes Estratégicos de Desarrollo tienen diferentes características, algunos son quinquenales, como el de Ecuador y Bolivia, aunque el último tenga un Plan General que es a 25 años. El de Perú es a 10 años y el de Guatemala a 20 años. Los planes de Bolivia y Guatemala han sido desarrollados con bastante minuciosidad llegando el de Bolivia hasta proponer indicadores de Resultado y el de Guatemala definido 730 lineamientos. Ecuador y Perú por su parte cuentan con un plan de muy 
alto nivel habiendo definido sólo ejes estratégicos y en el caso de Perú algunos lineamientos y prioridades. Una particularidad es que todos los países hacen énfasis en la revalorización de la cultura indígena excepto el Perú. Mayor información comparativa podremos encontrar en la Tabla 6: "Comparación de Planes Estratégicos de los países evaluados: Datos generales y concepto de Desarrollo", la misma que al igual que las otras tablas se encuentra en el anexo correspondiente por consideraciones de espacio y diseño del artículo.

\section{Tabla 6.}

Comparación de Planes Estratégicos de los países evaluados: Daros generales y concepto de Desarrollo

\begin{tabular}{|c|c|c|c|c|}
\hline & \multicolumn{4}{|c|}{ Países Evaluados } \\
\hline & Bolivia & Ecuador & Guatemala & Perú \\
\hline $\begin{array}{l}\text { Año de } \\
\text { Formulación }\end{array}$ & $\begin{array}{l}\text { Planes } \\
\text { quinquenales de } \\
\text { gobierno que se han } \\
\text { ido perfeccionando } \\
\text { en el tiempo, el } \\
\text { último emitido en } \\
\text { el } 2016 \text {. }\end{array}$ & $\begin{array}{l}\text { Planes } \\
\text { quinquenales } \\
\text { que se han ido } \\
\text { perfeccionando } \\
\text { en el tiempo. El } \\
\text { primero se formuló } \\
\text { en el } 2007 \text { y el } \\
\text { último emitido en } \\
\text { el } 2013 .\end{array}$ & $\begin{array}{l}\text { K'atun fue lanzado } \\
\text { el año } 2014\end{array}$ & $\begin{array}{l}\text { La primera } \\
\text { versión del Plan } \\
\text { Bicentenario al } \\
2021 \text { se emitió en } \\
\text { el año } 2011 \text { y el } 28 \\
\text { de junio del } 2016 \\
\text { fue actualizado } \\
\text { mediante } \\
\text { resolución } \\
\text { ministerial 138- } \\
\text { 2016-PCM. }\end{array}$ \\
\hline $\begin{array}{l}\text { Nombre del } \\
\text { Plan }\end{array}$ & $\begin{array}{l}\text { Plan de Desarrollo } \\
\text { Económico y } \\
\text { Social en el marco } \\
\text { del desarrollo } \\
\text { integral para "Vivir } \\
\text { Bien". } 2016 \text { - } 2020 .\end{array}$ & $\begin{array}{l}\text { Buen Vivir, Plan } \\
\text { Nacional de } \\
\text { Ecuador. Todo el } \\
\text { Mundo Mejor }\end{array}$ & $\begin{array}{l}\text { K'atún Nuestra } \\
\text { Guatemala al } 2032\end{array}$ & $\begin{array}{l}\text { El Plan Estratégico } \\
\text { de Desarrollo } \\
\text { Nacional - el Plan } \\
\text { Bicentenario al } \\
2021 .\end{array}$ \\
\hline $\begin{array}{l}\text { Ejes } \\
\text { Estratégicos, } \\
\text { número de } \\
\text { lineamientos } \\
\text { y Prioridades }\end{array}$ & $\begin{array}{l}\text { - Implementa los } 13 \\
\text { pilares de la agenda } \\
\text { patriótica. } \\
\text { - Plantea } 68 \text { metas y } \\
340 \text { indicadores de } \\
\text { resultado }\end{array}$ & $\begin{array}{l}12 \text { ejes estratégicos } \\
\text { con bastante } \\
\text { similitud a los } \\
\text { pilares de la agenda } \\
\text { patriótica de } \\
\text { Bolivia. }\end{array}$ & $\begin{array}{l}\text { Contempla } 5 \text { ejes } \\
\text { de Desarrollo, } \\
36 \text { prioridades, } \\
80 \text { metas, } 123 \\
\text { resultados y } 730 \\
\text { lineamientos. }\end{array}$ & $\begin{array}{l}\text { Contempla } 6 \text { ejes } \\
\text { de Desarrollo, } 6 \\
\text { lineamientos y } 14 \\
\text { prioridades }\end{array}$ \\
\hline $\begin{array}{l}\text { Concepto de } \\
\text { Desarrollo a } \\
\text { Implementar. }\end{array}$ & $\begin{array}{l}\text { Desarrollo } \\
\text { sostenible con } \\
\text { revalorización } \\
\text { ancestral. }\end{array}$ & $\begin{array}{l}\text { Desarrollo } \\
\text { sostenible con } \\
\text { revalorización de } \\
\text { la pluriculturalidad. }\end{array}$ & $\begin{array}{l}\text { Desarrollo } \\
\text { sostenible con } \\
\text { revalorización de } \\
\text { la pluriculturalidad. }\end{array}$ & $\begin{array}{l}\text { Desarrollo } \\
\text { sostenible sin } \\
\text { hacer énfasis en } \\
\text { la revalorización } \\
\text { pluricultural. }\end{array}$ \\
\hline
\end{tabular}




\begin{tabular}{|c|c|c|c|c|}
\hline & Bolivia & Ecuador & Guatemala & Perú \\
\hline Metodología. & $\begin{array}{l}\text { - Su formulación } \\
\text { es jerárquica } \\
\text { vertical, iniciando } \\
\text { en las altas esferas } \\
\text { del gobierno y se } \\
\text { despliega hacía los } \\
\text { niveles inferiores. } \\
\text { - No hacen uso de } \\
\text { Prospectiva. Se } \\
\text { hacen proyecciones } \\
\text { económicas } \\
\text { en función del } \\
\text { planteado en } \\
\text { la agenda al } \\
\text { bicentenario. }\end{array}$ & $\begin{array}{l}\text { - Orientación } \\
\text { descendente } \\
\text { - Activa } \\
\text { participación } \\
\text { ciudadana para } \\
\text { legalizar planes. } \\
\text { - Talleres zonales } \\
\text { de prospectiva para } \\
\text { identificación de } \\
\text { problemas. } \\
\text { - No se identifica } \\
\text { metodología } \\
\text { prospectiva. } \\
\text { - Modelo de } \\
\text { optimización } \\
\text { de múltiples } \\
\text { simulaciones para } \\
\text { determinar el nivel } \\
\text { de inversión por } \\
\text { distritos. }\end{array}$ & $\begin{array}{l}\text { - Orientación } \\
\text { ascendente. } \\
\text { - Activa } \\
\text { participación } \\
\text { ciudadana para } \\
\text { identificar } \\
\text { problemáticas } \\
\text { y proponer } \\
\text { soluciones. } \\
\text { - Consejos } \\
\text { comunitarios de } \\
\text { Desarrollo } \\
\text { - Mezcla de } \\
\text { diferentes } \\
\text { herramientas } \\
\text { prospectivas para } \\
\text { definir la visión de } \\
\text { futuro. } \\
\text { - Adaptación de } \\
\text { herramientas de } \\
\text { prospectiva para } \\
\text { poder ser usados } \\
\text { en los consejos de } \\
\text { menor nivel: “De } \\
\text { la computadora al } \\
\text { papel” }\end{array}$ & $\begin{array}{l}\text { - Orientación } \\
\text { descendente } \\
\text { - Indica } \\
\text { participación } \\
\text { de enfoque } \\
\text { prospectivo y } \\
\text { participativo. } \\
\text { Dentro del enfoque } \\
\text { participativo se } \\
\text { ha considerado el } \\
\text { académico no el } \\
\text { ciudadano. } \\
\text { - Se emplearon } \\
\text { algunas } \\
\text { herramientas de la } \\
\text { prospectiva (Delphi } \\
\text { y taller de expertos) } \\
\text { y econométricas } \\
\text { para la evaluación } \\
\text { de tendencias } \\
\text { (modelo IF's). } \\
\text { - La metodología } \\
\text { descrita no } \\
\text { se ajusta a la } \\
\text { metodología } \\
\text { Prospectiva a pesar } \\
\text { de implementar } \\
\text { algunas de sus } \\
\text { herramientas, } \\
\text { y el uso de } \\
\text { herramientas } \\
\text { econométricas } \\
\text { hacen pensar que } \\
\text { se ha empleado } \\
\text { Forecasting } \\
\text { en lugar de } \\
\text { Prospectiva a la } \\
\text { hora de definir su } \\
\text { visión. } \\
\end{array}$ \\
\hline $\begin{array}{l}\text { Inversiones } \\
\text { estratégicas }\end{array}$ & $\begin{array}{l}\text { Incluye las } \\
\text { inversiones a } \\
\text { realizar y define } \\
\text { el presupuesto de } \\
\text { ellos. }\end{array}$ & $\begin{array}{l}\text { Incluye las } \\
\text { inversiones a } \\
\text { realizar y define } \\
\text { el presupuesto de } \\
\text { ellos. }\end{array}$ & $\begin{array}{l}\text { Incluye las } \\
\text { inversiones a } \\
\text { realizar y define } \\
\text { el presupuesto de } \\
\text { ellos. }\end{array}$ & $\begin{array}{l}\text { Se menciona a } \\
\text { grandes rasgos. }\end{array}$ \\
\hline $\begin{array}{l}\text { Espíritu de la } \\
\text { planificación }\end{array}$ & $\begin{array}{l}\text { - Reivindicativa } \\
\text { de lo ancestral y } \\
\text { reconocimiento de } \\
\text { la pluriculturalidad. } \\
\text { - Independencia en } \\
\text { su desarrollo. } \\
\text { Vivir Bien. }\end{array}$ & $\begin{array}{l}\text { - Reivindicativa } \\
\text { de lo ancestral y } \\
\text { reconocimiento de } \\
\text { la pluriculturalidad. } \\
\text { - Redistribución } \\
\text { social de la riqueza. } \\
\text { Buen Vivir } \\
\end{array}$ & \begin{tabular}{|l|} 
- Reivindicativa \\
de lo ancestraly \\
reconocimiento de \\
la pluriculturalidad. \\
- Participación \\
Ciudadana. \\
- Cultura de Paz \\
\end{tabular} & $\begin{array}{l}\text { No se puede } \\
\text { identificar. }\end{array}$ \\
\hline
\end{tabular}

Fuente: Elaboración propia en base a la revisión de los planes de gobierno de cada país evaluado 
En cuanto a la metodología todos los países usan una metodología descendente excepto en Guatemala que es ascendente y es el único país que hace uso de la metodología de prospectiva desde sus más bajos niveles (no se puede verificar si se cumple). En el Perú a pesar de implementar algunas herramientas de Prospectiva, no se ajusta a la disciplina y el hecho de emplear herramientas econométricas hace pensar que se está empleando Forecasting. Respecto de Ecuador es claro el uso de modelos de optimización por múltiples simulaciones.

Se puede apreciar también que todos los planes excepto el de Perú hacen hincapié y precisión en cuanto a las inversiones Estratégicas y al espíritu que motiva su planificación.

\section{Conclusiones}

- Bolivia, Ecuador y Guatemala a diferencia de Perú hacen énfasis en la revalorización de su cultura ancestral, tal como se explica en la comparación de la Tabla 1.

- Sólo la constitución política de Bolivia considera la planificación como un tema prioritario para su legislación, por cuanto es explicita y se desarrolla en la misma. Ver Tabla 1.

- Bolivia, Ecuador, Guatemala y Perú cuentan con Sistemas de Planificación articulados en diferente medida y nivel, siendo el de Guatemala el más participativo con los consejos comunales, seguido del de Ecuador con sus mesas de diálogo. Al parecer en Bolivia y Perú la participación es limitada. Ver Tabla 4.

- En Bolivia, Ecuador y Guatemala la participación del Presidente es fundamental a la hora de impulsar la Planificación de Desarrollo, esta percepción se desprende desde la forma en que se ha conformado el sistema de planificación, dónde en Guatemala y Ecuador la oficina de planificación depende exclusivamente de la presidencia y en Bolivia es un ministerio. En Perú la participación presidencial prácticamente es nula, puesto que el encargado sería la presidencia del consejo de ministros, que ha delegado la función al CEPLAN pero con escaso nivel de influencia. Ver Tabla 5. 
- Las instituciones rectoras a cargo de la planificación tienen decisiones vinculantes en Bolivia, Ecuador y Guatemala. En Perú el ente rector de la planificación ha relegado su participación. Ver Gráfico 1.

- Los planes de gobierno de Bolivia, Ecuador y Guatemala, definen con precisión hasta el nivel de proyectos estratégicos de inversión con presupuesto a ser considerado. En el Perú, solo se definen áreas prioritarias de inversión. Ver Tabla 6.

- Los planes de desarrollo de Bolivia, Ecuador y Guatemala, en teoría son más fáciles de hacerles seguimiento y evaluación, por cuanto tienen claridad en lo que aspiran, ello se desprende del nivel alcanzado en la definición de los mismos. En el caso de Perú su Plan de Desarrollo es ambiguo y su nivel de definición sólo llega al alto nivel. Ver Tabla 6.

- En la elaboración de los Planes de Desarrollo de Bolivia y Ecuador se han utilizados herramientas de proyección econométricas, en el caso de Ecuador se menciona el uso de alguna herramienta Prospectiva para la identificación de problemas. En la elaboración del Plan de Desarrollo de Perú, se empleó una metodología que se aproxima al Forecasting y en la de Guatemala un mix de herramientas de Prospectiva bien definidos, ello se desprende de la evaluación que se hace de las metodologías seguidas por cada país. Ver Tabla 6.

- Perú ha retrocedido en su intención de contar con un sistema de Planificación Prospectivo robusto en todos sus niveles e instituciones de gobierno. Tal como lo muestran la directiva 001-2017-CEPLAN/PCD del 03 de mayo del 2017 y la resolución $\mathrm{N}^{\circ}$ 033-2017/CEPLAN/PCD del el 03 de junio del 2017.

\section{Recomendaciones}

- El revalorizar la identidad cultural ancestral puede contribuir a crear una sociedad con mayor identificación social. 
- Considerar modificar la constitución para darle mayor énfasis a la Planificación de Desarrollo en los casos del Perú y Ecuador.

- Se debe mejorar el nivel de participación de la sociedad civil a la hora de formular los planes de gobierno, ello creara apropiación de los mismos por la sociedad.

- El CEPLAN de Perú debería ser reorganizado, de modo tal que, alcance una mejor posición jerárquicay sus decisiones sean vinculantes con el resto de las instituciones del estado.

- El uso de herramientas de Prospectiva podría mejorar la evaluación de los escenarios a la hora de formular Planes de Desarrollo de Bolivia, Ecuador y Perú.

- El Plan de Desarrollo Nacional de Perú debería elaborarse con menos ambigüedades que permitan hacer un mejor seguimiento y evaluación de los resultados.

- El estado peruano debería reconsiderar la directiva 001-2017-CEPLAN/PCD y fortalecer la Planificación Prospectiva del país considerando que con ello asegura una visión social de futuro de consenso.

\section{Reconocimiento}

A la Mg Maria Peche Becerra, mi profesora en la maestría quién ha tenido la paciencia necesaria para darme el soporte cuando ha sido requerido. Su guía y aporte han sido necesarios para desarrollar el presente artículo.

\section{Bibliografía}

Burgwal, G y Cuellar JC (1999). Planificación Estratégica y Operativa aplicada a gobiernos locales. Manual de facilitación (1ra Ed.). Servicio holandés de cooperación al desarrollo. Ecuador.

CEPAL (2011). Espacios Iberoamericanos. Hacia una nueva arquitectura del Estado para el desarrollo. CEPAL, Naciones Unidas, Santiago de Chile.

CEPAL 2 (2015). América latina y el caribe en la agenda para el desarrollo después de 2015: Reflexiones preliminares basadas en la trilogía de la igualdad. CEPAL, Naciones Unidas, Santiago de Chile. Recuperado el 
01 de setiembre del 2017, de: http://repositorio.cepal.org/bitstream/ handle/11362/36804/1/S1420169_es.pdf.

CEPLAN (2011). Plan Bicentenario. El Perú hacía el 2021. Aprobado por el acuerdo Nacional .Ministerio de la Presidencia del Perú.

Cuesta, U. (2012). Planificación estratégica y creatividad. (1ra Ed.)España: Esic.

DNP-Colombia (2016). Plan Nacional de Desarrollo Colombia. Dirección Nacional de Planeamiento de Colombia. Recuperado el 01 de setiembre del 2017, de: https://www.dnp.gov.co/Plan-Nacional-de-Desarrollo/Paginas/Que-es-elPlan-Nacional-de-Desarrollo.aspx

Gamarra C, Kuan M y Guerra J. (2015). Mejoramiento de las capacidades de una brigada del ejército en guarnición y generación de valor público. Tesis maestría en Gestión Pública. Universidad del Pacifico. Perú.

ILPES (2013). Planificación para el desarrollo y la integración regional. Propuesta estratégica de mediano plazo para la cooperación del ILPES con los países de América Latina y el Caribe. XIV Reunión del Consejo Regional de Planificación del ILPES.

Katún 2032 (2014). Plan Nacional de Desarrollo K'atun Nuestra Guatemala 2032. Consejo Nacional de Desarrollo Urbano y Rural. Guatemala.

López Niño, D. (2016). El valor público y los acuerdos de integración económica en Colombia. Administración y Desarrollo, 46(1), 72-88. Recuperado el 01 de setiembre del 2017 de: http:// esapvirtual.esap.edu.co/ojs/index.php/ admindesarro/article/view/74.

Lucena Yamilleth (2014). Visión analítica de la planificación prospectiva en las universidades públicas venezolanas. Cuadernos de Administración / Facultad de Ciencias de la Administración / Universidad del Valle. Colombia

MDS- Bolivia (1996). El ordenamiento Territorial en Bolivia. Ministerio de Desarrollo Sostenible y Planificación. Bolivia.

Mera Rodríguez, Carlos (2014). Pensamiento prospectivo: visión sistémica de la construcción del futuro. ANÁLISISVol 46, No. 84. P.89-104. Colombia. Recuperado el 01 de setiembre del 2017 de:http://docplayer.es/30044729Analisis-issn-vol-46-no-84-bogota-ene-jun-2014-pp-recibido-16-deagosto-de-2013-aprobado-30-de-enero-de-2014.html.

Monje Antonio (2014). Cooperación internacional, descentralización y participación ciudadana. La gestión de la asistencia oficial para el desarrollo desde los gobiernos autónomos descentralizados en el Ecuador. CEPAL. 
Recuperado el 01 de setiembre del 2017 de:http://repositorio.cepal.org/ bitstream/handle/11362/36632/S2014041_es.pdf?sequence=1.

Naser A y Conche G (2014). Rol de las TIC en la gestión pública y en la planificación para un desarrollo sostenible en América Latina y el Caribe. CEPAL. Recuperado el 01 de setiembre del 2017 de: http://repositorio.cepal.org/ handle/11362/35951.

Ramírez Gálvis y Gloria Patricia (2012). Los problemas y desafíos en la integración de la Planificación Prospectiva con la planificación estratégica situacional: el caso del plan decenal de educación del municipio de Guarujá - Brasil. Tesis de Maestría. Universidad del Valle. Colombia.

Reyna L, Reyna M y Reyna J (2014). Plan de desarrollo y ordenamiento territorial, como herramienta para el desarrollo sustentable: Estudio de caso en Esmeraldas, Ecuador. Recuperado el 17 de enero del 2017 de: http:// revistas.utm.edu.ec/index.php/latecnica/article/view/360

Sangabriel Rivera, Mavil Aguilera y Mendez Anata (2015). La Prospectiva Estratégica: un acercamiento teórico. Revista Ciencia Administrativa (vol. 2). Universidad Veracruzana. México. Recuperado el 01 de setiembre del 2017 de: http://revistas.uv.mx/index.php/cadmiva/article/view/2059.

Sainz de Vicuña José Maria (2015). Plan estratégico en la práctica. (4ta Ed.). ESIC, España.

SHCP (2013). Plan Nacional de Desarrollo 2013-2018. Secretaría de Hacienda y Crédito público. México. Recuperado el 01 de setiembre del 2017 de: http:// itcampeche.edu.mx/wp-content/uploads/2016/06/Plan-Nacional-deDesarrollo-PND-2013-2018-PDF.pdf.

Tassara, Carlo (2014) Planificación estratégica, administraciones locales y desarrollo territorial: una experiencia de la cooperación eurolatinoamericana en Colombia. IberoamericanJournal of DevelopmentStudies, 3 (2): 50-79.

Trefogli Wong, Guillermo Antonio (2013). Gestión estratégica y creación de valor en el sector público: estudio de caso sobre el desarrollo de evaluaciones de conocimientos en el servicio civil peruano (2008-2012). Tesis Licenciatura en Gestión Pública. PUCP-Perú.

Vergara, Rafael (2016). El Plan de Ordenamiento Territorial (POT) de Cali, una aproximación. Universidad Politécnica Tecnológica de Colombia. Recuperado el 01 de setiembre del 2017 de: http://revistas.uptc.edu.co/ index.php/cenes/article/view/4271/4305 
Ministerio del Ambiente (MINAM). Plan de ordenamiento territorial (POT). Recuperado el 20 de agosto del 2017 de: http://www.minam.gob.pe/ ordenamientoterritorial/instrumentos-tecnicos-para-el-ordenamientoterritorial/plan-de-ordenamiento-territorial-pot 